\title{
Regolith-Derived Heat Shield for Planetary Body Entry and Descent System with In Situ Fabrication
}

\author{
Michael D. Hogue ${ }^{1}$, Robert P. Mueller ${ }^{2}$, Daniel Rasky ${ }^{3}$, Paul Hintze $^{4}$, Laurent Sibille ${ }^{5}$ \\ 1 Electrostatics \& Surface Physics Laboratory, NE-S-1, NASA, Kennedy Space Center, FL \\ 32899. (321) 867-7549, email: Michael.D.Hogue@nasa.gov. \\ 2 Surface Systems Office, NE-S, NASA, Kennedy Space Center, FL 32899. Email: \\ Robert.P.Mueller@nasa.gov. \\ ${ }^{3}$ Emerging Space Office, NASA, Ames Research Center. \\ 4 Corrosion Laboratory, NE-L, NASA, Kennedy Space Center, FL 32899. Email: \\ Paul.E.Hintze@nasa.gov \\ ${ }^{5}$ QNA ESC, Kennedy Space Center, FL 32899. Email: Laurent.sibile-1@nasa.gov.
}

E-Mail: Michael.D.Hogue@nasa.gov

\begin{abstract}
In this paper we will discuss a new mass-efficient and innovative way of protecting high-mass spacecraft during planetary Entry, Descent \& Landing (EDL). Heat shields fabricated in situ can provide a thermal-protection system (TPS) for spacecraft that routinely enter a planetary atmosphere. By fabricating the heat shield with space resources from regolith materials available on moons and asteroids, it is possible to avoid launching the heat-shield mass from Earth. Three regolith processing and manufacturing methods will be discussed: 1) oxygen \& metal extraction ISRU processes produce glassy melts enriched in alumina and titania, processed to obtain variable density, high melting point and heat-resistance; 2) compression and sintering of the regolith yield low density materials; 3) in-situ derived high-temperature polymers are created to bind regolith particles together, with a lower energy budget.
\end{abstract}

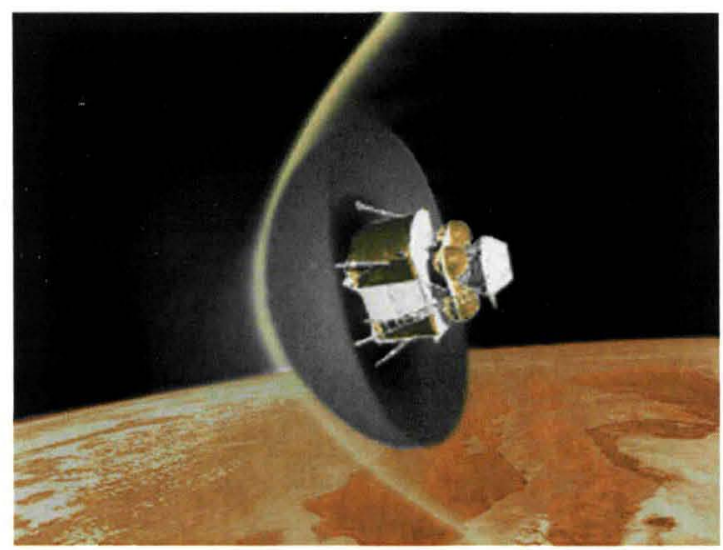

Artists' concept of a regolith derived re-entry heat shield. 


\title{
Regolith-Derived Heat Shield for Planetary Body Entry and Descent System with In Situ Fabrication
}

\author{
Michael D. Hogue ${ }^{1}$, Robert P. Mueller ${ }^{2}$, Paul E. Hintze ${ }^{3}$, Laurent Sibille ${ }^{4}$, Daniel J. \\ Rasky $^{5}$
}

${ }^{1}$ NASA, Electrostatics \& Surface Physics Laboratory, NE-S-1, Kennedy Space Center, FL 32899; Ph (321) 867-7549; e-mail: Michael.D.Hogue@nasa.gov.

${ }^{2}$ NASA, Surface Systems Office, NE-S, Kennedy Space Center, FL 32899; Ph (321)

867-2557; e-mail: Rob.Mueller@nasa.gov.

${ }^{3}$ NASA, Corrosion Laboratory, NE-L, Kennedy Space Center, FL 32899; Ph (321)

867-3751; e-mail: Paul.E.Hintze@nasa.gov.

${ }^{4}$ ESC QinetiQ North America, Kennedy Space Center, FL 32899; Ph (321) 867-4422;

e-mail: Laurent.Sibille-1@nasa.gov.

${ }^{5}$ NASA, Emerging Space Office, Ames Research Center, Moffett Field, CA 94035;

Ph (650) 604-1098; e-mail: Daniel.J.Rasky@nasa.gov.

\begin{abstract}
In this paper we will discuss a new mass-efficient and innovative way of protecting high-mass spacecraft during planetary Entry, Descent \& Landing (EDL). Heat shields fabricated in situ can provide a thermal-protection system (TPS) for spacecraft that routinely enter a planetary atmosphere. By fabricating the heat shield with space resources from regolith materials available on moons and asteroids, it is possible to avoid launching the heat-shield mass from Earth. Three regolith processing and manufacturing methods will be discussed: 1) oxygen \& metal extraction ISRU processes produce glassy melts enriched in alumina and titania, processed to obtain variable density, high melting point and heat-resistance; 2) compression and sintering of the regolith yield low density materials; 3) in-situ derived high-temperature polymers created to bind regolith particles together, with a lower energy budget.
\end{abstract}

\section{INTRODUCTION}

Routine access to space and return from any planetary surface requires dealing with heat loads experienced by the spacecraft during reentry. This paper will address some of the key issues with the entry, descent, and landing (EDL) of human-scale missions through a highly innovative investigation of heat shields that can be fabricated in 
space by using local resources on asteroids and moons. Most space missions are oneway trips, dedicated to placing an asset in space for economical or scientific gain. However, for human missions, a very-reliable heat-shield system is necessary to protect the crew from the intense heat experienced at very high entry velocities of approximately $11 \mathrm{~km} / \mathrm{s} \sim$ Mach 33 (Apollo). For a human mission to Mars, the return problem is even more difficult, with predicted velocities of up to $14 \mathrm{~km} / \mathrm{s}, \sim$ Mach 42 at the Earth-atmosphere entry. In addition to human return, it is very likely that future space-travel architecture will include returning cargo to the Earth, either for scientific purposes or for commercial reasons. Platinum, titanium, helium 3, and other metals and minerals are all high-value commodities in limited supply on Earth, and it may be profitable to mine these substances throughout the Solar System and return them to Earth, if an economical method can be found. Because the heat shield is the last element to be used in an Earth-return mission, a high penalty is paid in the propellant mass required to carry the heat shield to the destination and back. If the heat shield could be manufactured in space, and then outfitted on the spacecraft prior to the reentry at Earth, then significant propellant and mass savings could be achieved during launch and space operations.

The Earth-return scenario is just one aspect of thermal-protection requirements for spacecraft. Travel to any planet with an atmosphere will also require heat shields. The stated goal of NASA is to send humans to Mars [1]. If a heat shield is sent to Mars, then there is a huge penalty to pay for this launch mass at Earth, because for every kilogram sent to Mars orbit, there is a so-called "gear ratio" of mass in low earth orbit (LEO). A gear ratio is the mass required in LEO to deliver one mass unit to the orbit of or on the surface of an extraterrestrial body. Using only propulsive transfers, the gear ratios for transfer from LEO (i) to Mars-circular orbit range from 5.4 to 7.6, (ii) to Mars-elliptical orbit range from 4.2 to 5.4 , and to the surface of Mars range from $\sim 20$ to 40 , depending on the propulsion system and the transfer trajectory. Using full aero-assist at Mars, with LOX-LH2 propulsion used for Earth departure, the gear ratio for transfer from LEO to Mars-circular orbit is $\sim 4.6$ to 5.0, and the gear ratio for transfer from LEO to the Mars surface is $\sim 10$ to 11 [2].

An all-propulsive mission to Mars would require a gear ratio of 20, but it is highly likely that some form of aerocapture would be used. This will lower the gear ratio, but does require an appropriate heat shield. Assuming a conservative aerocapture gear ratio of 5, then each $\mathrm{kg}$ at Mars orbit requires $5 \mathrm{~kg}$ to be injected from LEO.

The Mars NASA DRA 5.0 [1] assumes an aeroshell structure and associated thermalprotection system (TPS) mass of 40.7 metric tons ( 37 percent of Mars orbit mass!). If this is used as a benchmark, then it can be stated that using an in-situ-derived heat shield will save a large mass by avoiding the system mass required for transportation 
from Earth to Mars. Using a gear ratio of 5, the LEO to Mars mass transportation savings is 203.5 metric tons (9 Delta IV Heavies @ 22.5t each). If the launch cost of the Space Shuttle is used ( $\$ 10,000$ per pound $/ \$ 22,000 / \mathrm{kg})$, then this results in a cost avoidance of $\$ 4.47$ billion per launch manifest. Even if expendable launch vehicles were used at a cost of about $\$ 4,000 /$ pound $(\$ 8,800 / \mathrm{kg})$, the cost avoidance would still be $\$ 1.79$ billion per launch manifested. Since a future human mission architecture assumes multiple missions, and then cost avoidance will be even higher. If two surface missions are assumed per Mars journey (ascent vehicle and crew launched separately), then the launch cost avoidance of using an in-situ-fabricated heat shield will be between $\$ 3.58$ billion to $\$ 8.94$ billion, depending on the launch costs. Table 1 shows mass budget estimates from the Mars DRA 5.0 [1].

\section{Table 1: NASA Mars DRA 5.0 Mass Budget Estimates (Data from [1])}

\section{EDL Mass Summary}

\begin{tabular}{|lr|}
\hline Orbit Mass & $\mathbf{1 1 0 . 2 ~ t}$ \\
Deorbit Propellant & $0.5 \mathrm{t}$ \\
\cline { 2 - 2 } Entry Mass & $\mathbf{1 0 9 . 7 ~ t}$ \\
Aeroshell Structure & $22.5 \mathrm{t}$ \\
Thermal Protection System & $18.2 \mathrm{t}$ \\
RCS Dry Mass & $1.0 \mathrm{t}$ \\
RCS Propellant & $1.2 \mathrm{t}$ \\
Terminal Descent Propellant & $10.1 \mathrm{t}$ \\
\cline { 2 - 2 } Landed Mass & $\mathbf{5 6 . 8 ~ t}$ \\
Dry Descent Stage & $16.4 \mathrm{t}$ \\
\cline { 2 - 2 } Payload Mass & $\mathbf{4 0 . 4 ~ t}$ \\
\hline
\end{tabular}

\section{EDL System Characteristics}

\begin{tabular}{|lcc|}
\hline Deorbit Delta-v & 15 & $\mathrm{~m} / \mathrm{s}$ \\
Ballistic Coefficient & 471 & $\mathrm{~kg} / \mathrm{m}^{2}$ \\
Descent Delta-v & 595 & $\mathrm{~m} / \mathrm{s}$ \\
Max Heat Rate & 131 & $\mathrm{~W} / \mathrm{cm}^{2}$ \\
Total Heat Load & 172 & $\mathrm{MJ} / \mathrm{m}^{2}$ \\
Altitude Engine Initiation & 1,350 & $\mathrm{~m}$ \\
Mach @ Engine Initiation & 2.29 & \\
Time of Flight & 486 & $\mathrm{sec}$ \\
Time at Constant g's & 134 & $\mathrm{sec}$ \\
Engine T/W & 161 & $\mathrm{~N} / \mathrm{kg}$ \\
& &
\end{tabular}

\section{IMPLICATIONS FOR SPACE ARCHITECTURE}

It may be argued that the cost of fabricating heat shields in space at asteroids, or moons such as Phobos, exceeds the savings of launching from Earth. This research will investigate the feasibility of making in-situ-derived heat shields, and will then assess the architectural implications and economic benefits of doing so to see if the architecture and business case can be closed. This is not a simple trade-study because the full life cycle of the proposed space campaign must be assessed. Our team will use NASA Mars DRA 5.0 as a point of departure for relative benchmarking and will also investigate other candidate architectures deemed to be beneficial or of interest to NASA. Just as the life-cycle costs of operating the Space Shuttle have far outweighed the design, development, test, and engineering of the Shuttle, it is the life-cycle costs that will show the benefit of in-situ-fabricated heat shields. Imagine a space campaign to Mars with 10 crew rotations. At two Mars landings per Mars mission, this amounts to 20 heat shields that must be transported to Mars. If these heat shields were manufactured and outfitted at Phobos as a Mars staging point, then the 
associated cost savings would be between $\$ 35.8$ billion and $\$ 89.4$ billion, and will enable smaller launch vehicles to be used.

Another problem with heat shields planned today for human Mars missions is that their desired diameter and length exceed the capabilities of the largest heavy-lift launch vehicle payload shroud available. For a 50-100 metric ton spacecraft at Mars entry, heat shields with a diameter of 20-40 meters are required. The largest shroud planned for a heavy-lift launch vehicle is 5 meters, so it is not possible to package these heat shields in a launch vehicle. Many compromise solutions have been proposed, such as using inflatable ballute heat shields or a long-ellipsled configuration, but these compromises are completely eliminated if the heat shield is fabricated in space to the exact specifications of the aero-thermal design community. By removing the launch-shroud constraint, a completely new approach to EDL will be enabled.

In addition, if Phobos were used as a propellant depot staging point and the propellants were manufactured from water on Mars, then a propellant transportation cycler system could be set up with expendable heat shields also fabricated on Phobos and outfitted to each Mars propellant cargo lander as they shuttle back and forth from the Mars surface providing propellants to the depot at Phobos for Solar System transportation. This capability would provide a revolutionary change to the way space architectures are designed today, and may be enabling for a shift to more costeffective space operations which will benefit humans through the establishment of space-based services such as energy-capture for Earth and resource-mining for Earthbased enterprises.

The same in situ heat shield technology proposed for Mars missions can be used to access the outer Solar System, where substantial water, metal, and mineral resources are available. Many moons in the Jovian system and the planets in the outer Solar System have atmospheres that must be conquered. Once the resources have been mined, then they can be transported back to Earth, where once again, a heat shield will be required to return these lucrative cargos for human use. The initial investment in heat-shield fabrication technology and capabilities in space will result in multiple ways to exploit them for the benefit of innovative and revolutionary architectures that will completely change the way we approach space travel. In addition, since the heatshield mass does not have to be launched from Earth, then the heat shield can be designed with substantial performance margins, making it much safer for the crew and cargo that will rely on this critical thermal protection system for a safe landing. 


\section{EXISTING HEAT SHIELD STATE OF THE ART}

Many different types of heat-shield configurations and materials have been used. Some of the various heat shield materials from past and present spacecraft and their properties are listed in Table 2.

The TPS materials available for the Mars aeroshell forebody heat shield were phenolic-impregnated carbon ablator (PICA) and LI 2200. PICA is a candidate Orion/CEV ablator being developed for both the LEO and lunar return missions. PICA was the required TPS to account for the relatively high heating rates (462 $\mathrm{W} / \mathrm{cm} 2$ ) experienced during the aerocapture phase. For the leeward surfaces exposed to less severe thermal environments, heritage shuttle TPS materials were selected, including LI-900 and felt reusable surface insulation (FRSI) blankets [3].

Table 2: Selected Past and Current Ablative Heat Shields [4][5][6][11]

\begin{tabular}{|c|c|c|c|c|c|}
\hline Material & Description & Manufacturer & $\begin{array}{l}\text { Method of } \\
\text { Construction }\end{array}$ & $\begin{array}{c}\text { Maximum } \\
\text { Heat Flux } \\
\left(\mathrm{W} / \mathrm{cm}^{2}\right) \text { or } \\
\text { Temperatu } \\
\text { re }\left({ }^{\circ} \mathrm{C}\right)\end{array}$ & $\begin{array}{l}\text { System } \\
\text { used on }\end{array}$ \\
\hline $\begin{array}{l}\text { SLA- } \\
561 \mathrm{~V}\end{array}$ & $\begin{array}{l}\text { Proprietary } \\
\text { Super Light } \\
\text { weight } \\
\text { Ablator } \\
\end{array}$ & $\begin{array}{l}\text { Lockheed } \\
\text { Martin }\end{array}$ & $\begin{array}{l}\text { SLA- } 561 \mathrm{~V} \text { packed } \\
\text { into a honeycomb } \\
\text { core prebonded to } \\
\text { the aeroshell. }\end{array}$ & $300 \mathrm{~W} / \mathrm{cm}^{2}$ & $\begin{array}{c}\text { Mars } \\
\text { Science } \\
\text { Laborator } \\
\text { y }\end{array}$ \\
\hline PICA & $\begin{array}{c}\text { Phenolic } \\
\text { Impregnated } \\
\text { Carbon } \\
\text { Ablator } \\
\end{array}$ & $\begin{array}{l}\text { NASA Ames } \\
\text { Research } \\
\text { Center (ARC) }\end{array}$ & $\begin{array}{l}\text { Fibrous carbon } \\
\text { preform pore-filled } \\
\text { into a high-surface- } \\
\text { area phenolic resin }\end{array}$ & $1200 \mathrm{~W} / \mathrm{cm}^{2}$ & Stardust \\
\hline $\begin{array}{c}\text { PICA-X } \\
\text { [3] }\end{array}$ & $\begin{array}{c}\text { Phenolic } \\
\text { Impregnated } \\
\text { Carbon } \\
\text { Ablator } \\
\end{array}$ & Space-X, ARC & $\begin{array}{l}\text { Fibrous carbon } \\
\text { preform pore-filled } \\
\text { into a high-surface- } \\
\text { area phenolic resin }\end{array}$ & $1850^{\circ} \mathrm{C}$ & $\begin{array}{l}\text { Dragon } \\
\mathrm{C} 1\end{array}$ \\
\hline SIRCA & $\begin{array}{c}\text { Silicone } \\
\text { Impregnated } \\
\text { Reusable } \\
\text { Ceramic } \\
\text { Ablator } \\
\end{array}$ & NASA ARC & $\begin{array}{l}\text { Machined to custom } \\
\text { shapes }\end{array}$ & $\sim 700 \mathrm{~W} / \mathrm{cm}^{2}$ & $\begin{array}{c}\text { Mars } \\
\text { Pathfinder } \\
\text {, Mars } \\
\text { Exploratio } \\
\text { n Rover }\end{array}$ \\
\hline AVCOAT & $\begin{array}{l}\text { Glass-filled } \\
\text { epoxy- } \\
\text { novalic }\end{array}$ & $\begin{array}{c}\text { Avco } \\
\text { (acquired by } \\
\text { Textron, 1984) }\end{array}$ & $\begin{array}{l}\text { Empty honeycomb } \\
\text { bonded to frame } \\
\text { then material is } \\
\text { pressed in }\end{array}$ & $\begin{array}{l}\sim 1,400 \\
W / \mathrm{cm}^{2}\end{array}$ & $\begin{array}{l}\text { Apollo } \\
\text { capsule, } \\
\text { Orion }\end{array}$ \\
\hline LI-900 & $\begin{array}{l}\text { Lightweight } \\
\text { silica fibers } \\
\text { coated with } \\
\text { borosilicate } \\
\text { glass }\end{array}$ & Lockheed & $\begin{array}{l}\text { Tiles glued to } \\
\text { airframe via RTV } \\
\text { adhesive }\end{array}$ & $\sim 1,649^{\circ} \mathrm{C}$ & $\begin{array}{l}\text { Space } \\
\text { Shuttle }\end{array}$ \\
\hline
\end{tabular}




\section{FEASIBILITY}

To model the heat transfer through the regolith, the physical properties and characteristics of the regolith heat-shield material must be known. These properties include thermal conductivity, specific heat, latent heat, density, and meltingtemperature range. Accurate modeling of each property is very important because it is these physical properties that dictate how the regolith will behave when heated. The regolith is in granular form up to a temperature of $1,373 \mathrm{~K}$, where it will begin to melt. Since the regolith is a mixture of compounds, it melts over a range of temperatures. This melting temperature range is $1,373 \mathrm{~K}$ to $1,653 \mathrm{~K}$ (Langseth et al., 1973) [14]. Above $1,653 \mathrm{~K}$, the regolith is completely molten.

To determine whether regolith can be used as a heat-shield material, lunar highlands regolith simulant will be used as an initial material, since not much is known about regolith on asteroids or Phobos. Because lunar regolith is more than 90 percent silicate minerals and $\mathrm{SiO}_{2}$ melts at $1,995 \mathrm{~K}$ (upper bound), experiments will be conducted to show that a heat shield made of regolith can endure stagnation temperatures during atmospheric entry between $1,653 \mathrm{~K}$ and $1,995 \mathrm{~K}$. Since regolithbased ablative heat shields may achieve temperatures as high as 3,000 K, at which point $\mathrm{O}_{2}$ thoroughly dissociates from $\mathrm{Si}$, it may be possible to design an ablative heat shield that reaches temperatures up to $3,000 \mathrm{~K}$. However, the rate at which regolith layers ablate or are removed is dependent on the heat flux, not necessarily just the temperature. What this means is that the regolith ablator might work, even if it only withstands $500 \mathrm{~K}$, if it is thick enough. These experiments in the lab and at the Ames Research Center (ARC) arc jet facility will show whether regolith is suitable as a heat-shield material. Various regolith formation and manufacturing methods will be investigated and traded-off against each other. Regolith heat-shield coupons will be tested in an arc jet facility at ARC to model the high heat and molecular impact stresses [11][12][13][15][16].

\section{DESCRIPTION OF REGOLITH HEAT SHIELD FABRICATION METHODS}

\section{In Situ Resource Utilization (ISRU) Products.}

Several technologies currently under development yield silicate-based by-products by processing planetary regolith to extract oxygen and metal [7]. The chemical reduction of metal oxides by reaction with hydrogen demonstrated in laboratory and field tests show that a partially sintered granular material is obtained at temperatures near $900 \mathrm{C}$ Fig. 1 shows reduced Hawaiian tephra coming out of the roxygen generation I reactor [17]. The oxide composition of the processed material is nearly that of the indigenous regolith fed to the reactor minus the amount of iron oxide and iron-titanium oxide (Ilmenite) reduced by the hydrogen. Further processing of the reduced regolith exiting 
the reactor may consist of rapid sintering under pressure to obtain shaped components of a heat shield or using it as matrix component mixed with a polymer fiber component to yield a composite heat-shield material. Regolith materials, reduced chemically by carbon in the form of methane, have also progressed technologically in the recent years [18]. The processing temperatures near $1700 \mathrm{C}$ yield a fully molten oxide product that is recovered as a glass after cooling. The reaction of oxide components with carbon at high temperatures also yields carbide molecules and fully reduced metal particles. The molding of adequate shapes for heat shield purposes is done directly in the bed of non-processed regolith and allows for easy recovery or the pieces. To this date, the technology has not been scaled for melts larger than a few kilograms.

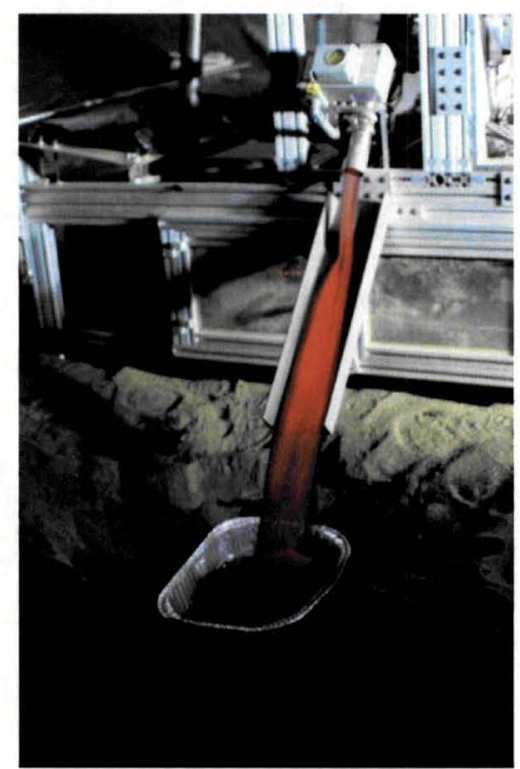

Figure 1. Hot Hawaiian tephra coming out of the roxygen generation I reactor.

A third regolith processing technology being developed is Molten Regolith Electrolysis [19], also called Magma Electrolysis. The reduction of the regolith oxides is achieved by direct electrolysis in the oxide melt and does not involve the addition of chemical reducing agents. At processing temperatures of $1600 \mathrm{C}$, the technique reduces all sodium and iron oxides and about half of the silicon oxide of the regolith thus yielding a melt enriched in compounds such as magnesium, aluminum and titanium oxides. The melt is retrieved from the reactor in liquid form suitable for casting in suitable shapes. Since it is a fully densified glass product, its structural strength may need to be augmented by the incorporation of fiber components during casting or via layering with sintered material.

\section{Sintered Regolith.}

Sintering is a process where powdered material is heated until it fuses into a solid. It is a common method for making ceramics. The sintering process has been proposed 
for making building materials and structures using regolith on the Earth's moon and other planetary surfaces [8][9][10]. The process is desirable because it requires only a heat source be brought from Earth and can be used on regolith with minimal if any processing. A schematic sequence of the sintering process is shown in Fig. 2A.

Sintering has been demonstrated in laboratory and field studies on lunar regolith simulants [8][20][21]. Fig. 2B shows an image of sintered tiles made from JSC-1AC lunar simulant placed on a bed of lunar simulant. Although some physical testing of sintered simulants has been done, the thermal properties that would demonstrate that sintered regolith is appropriate as a heat shield have not been measured.
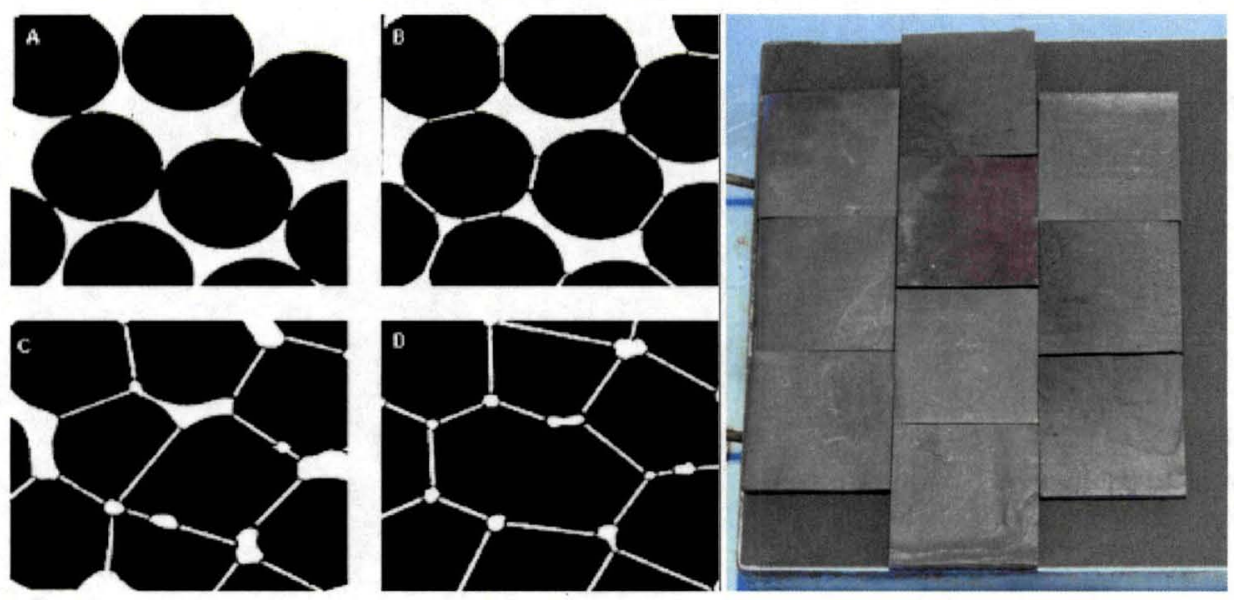

A.

B.

Figure 2. A: Schematic sequence $(A-D)$ of the sintering process. B: Sintered JSC1 A tiles [20].

\section{In Situ Derived Polymer Bound Regolith.}

Polymers have been used to bind lunar simulants [8][14]. Polymer/regolith composite materials have been made using less than 5 percent polymer by mass using formulations of conventional polymers. Previous work on these composite materials has focused on making structural materials, and not on optimizing thermal properties. In situ derived polymers may also be used as a binder for a polymer/regolith composite. The in situ polymers may be derived from volatiles present on planetary bodies or may be found on asteroids or moons that contain the kerogen-like organic material that has been found in carbonaceous chondrites. A tile made from lunar regolith simulant and a terrestrial polymer binder is shown in Fig. 3. 


\section{TESTING}

Several coupons for each of the fabrication methods will be made. Some coupons will be used to measure the physical properties of the resulting materials like hardness, density, shear, etc. Other coupons will be sent to Ames Research Center for testing in its arc jet facility. This facility can model the aerodynamic and thermodynamic loads a heat shield experiences upon atmospheric entry. Fig. 4 shows a heat shield coupon undergoing testing in the arc jet facility.

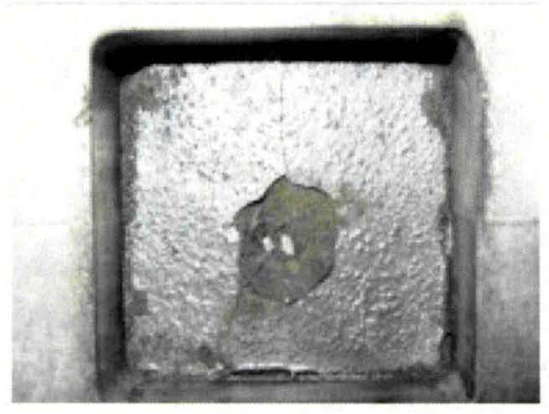

Figure 3. Prototype regolith/polymer tile.

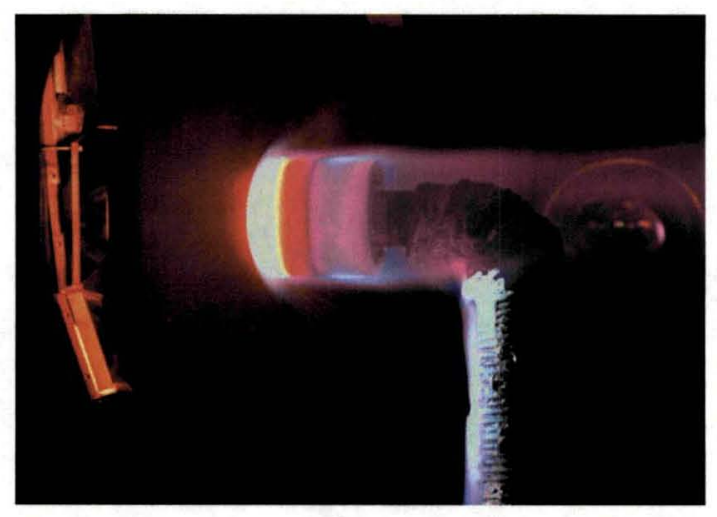

Figure 4. Heat shield coupon undergoing testing in the NASA Ames arc jet facility.

\section{CONCLUSION}

Building a viable heat shield from regolith via an ISRU process will enhance the current state of the art. New forming-processes will need to be developed to build reentry heat shields from raw extraterrestrial materials in space. These new processes could apply to creating other structural components and systems from regolith. Very little is known about using regolith as a heat shield, but the basic properties of regolith indicate that it may be possible to create an in situ heat shield in space with major architectural implications. Large mass-savings in the architecture are possible with corresponding cost savings. In-situ fabrication methods will allow many 
different parts to be made in space. Due to the relatively high-mass fraction of this component in Mars and Earth return missions, the highest reward may come from building heat shields in space. Implementing this innovative approach would completely change the Mars Design Reference Architecture to reduce life cycle costs of recurring operations at Mars. These new TPS systems could be implemented within the same time-frame as a potential Mars mission beyond 2030.

\section{ACKNOWLEDGEMENT}

The authors wish to acknowledge the support of NASA, Kennedy Space Center, NASA, Ames Research Center, and the National Institute for Advanced Concepts (NIAC) for their support of this work.

\section{REFERENCES}

[1] NASA SP-2009-566, Human Exploration of Mars, Design Reference Architecture (DRA) Mars 5.0, July 2009.

[2] Rapp, D., MARS 1, 1-6, 200, 5; Mars Journal 2005. http://marsjournal.org

[3] A. Edwards, G. Hautaluoma, K. Clem, Release 09-080, NASA website: http://www.nasa.gov/home/hqnews/2009/apr/HQ 09080 Orion Heat Shield.html.

[4] Atmospheric Entry, Wikipedia, http://www.spaceref.com/news/viewpr.html.

[5] Space X, "Space X Manufacture Heat Shield Material Passes High Temperature Tests Simulating Reentry Heating Conditions of Dragon Spacecraft", http://www.spaceref.com/news/viewpr.html.

[6] Space Shuttle Thermal Protection System, Wikipedia website: http://en.wikipedia.org/wiki/Space_Shuttle_thermal_protection_system

[7] L. Sibille, et. al., "Recent Advances in Scale-up Development of Molten Regolith Electrolysis for Oxygen Production in support of a Lunar Base", AIAA 2009-659, 47th AIAA Aerospace Sciences Meeting, 5 - 8 January, 2009, Orlando, FL.

[8] P. Hintze, J. Curran, T. Black, "Lunar Surface Stabilization via Sintering or the use of Heat Cured Polymers", AIAA 2009-1015, 47th AIAA Aerospace Sciences Meeting, 5 - 8 January, 2009, Orlando, FL.

[9] L. Roberson, P. Hintze, G. O'Connor, "A Conceptual Study for the Autonomous Direct Forming of Lunar Regolith into Flexlock ${ }^{\mathrm{TM}}$ Geomats for Lunar Surface Operations". AIAA 2009-1013, 47th AIAA Aerospace Sciences Meeting, 5 - 8 January, 2009, Orlando, FL.

[10] V. Balla, et. al.,"First Demonstration on Direct Laser Fabrication of Lunar Regolith Parts", submitted to the Rapid Prototyping Journal, April, 2011.

[11] B. Laub, E. Venkatapathy, Thermal Protection System Technology and Facility Needs for Demanding Future Planetary Missions, Proceedings International 
Workshop on Planetary Probe Atmospheric Entry and Descent Trajectory Analysis and Science, Lisbon, Portugal, 6-9 October, 2003.

[12] J. Lachaud, I. Cozmuta, N. Mansour, Multiscale Approach to Ablation Modeling of Phenolic Impregnated Carbon Ablators, Journal OF Spacecraft and Rockets, Vol. 47, No. 6, November-December 2010.

[13] S. Berry, T. Horvath, R. Lillard, B. Kirk, A. Cassady, "Aerothermal Testing for Project Orion Crew Exploration Vehicle", AIAA 2009-3842, 441 ${ }^{\text {st }}$ AIAA Thermophysics Conference, 22 - 25 June 2009, San Antonio, Texas.

[14] Langseth M. G. et. al. (1973) Apollo 15 Prelim. Sc. Rept., 9-1-23.

[15] D. Kinney, "Development of the ORION Crew Exploration Vehicle's Aerothermal Database Using a Combination of High Fidelity CFD and Engineering Level Methods", AIAA Paper 2009-1100, Jan. 2009.

[16] NASA Ames Research Center Thermo-Physics Facilities Branch Fact Sheet, http://thermo-physics.arc.nasa.gov/fact_sheets/Range\%20Fact\%20Sheet.pdf.

[17] B. Keller, D. Clark, J. Kirkland, "Field Test Results of the PILOT Hydrogen Reduction Reactor," AIAA-2009-6475, AIAA SPACE 2009 Conference and Exposition, Pasadena, California, Sep. 14-17, 2009

[18] R. Gustafson, B. White, M. Fidler, "Analog Field Testing of the Carbothermal Regolith Reduction Processing System," AIAA-2011-434, 49th AIAA Aerospace Sciences Meeting including the New Horizons Forum and Aerospace Exposition, Orlando, Florida, Jan. 4-7, 2011

[19] L. Sibille, D.R. Sadoway, A. Sirk, P. Tripathy, O. Melendez, E. Standish, J. A. Dominguez, D. M. Stefanescu, P. A. Curreri, and S. Poizeau, "Recent Advances in Scale-Up Development of Molten Regolith Electrolysis for Oxygen Production in Support of a Lunar Base" AIAA 2009-659, Proceedings of the 47th AIAA Aerospace Sciences Meeting, Orlando, Florida, Jan. 5-8, 2009.

[20] Hintze, P. E. (2010) "Building a Vertical Take Off and Landing Pad using in situ Materials." Proceedings of Space Manufacturing 14, Space Studies Institute, Mojave, CA.

[21] Hintze, P. E., Quintana, S. "Building a Lunar or Martian Launch Pad with in situ Materials: Recent Laboratory and Field Studies.", Journal of Aerospace Engineering, in press. 


\section{Regolith Derived Heat Shield for Planetary Body Entry and Descent System with In Situ Fabrication}

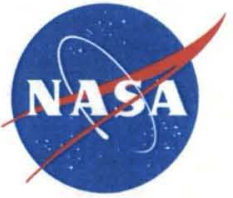

\section{Introduction}

High-mass planetary surface access is one of NASA's Grand Challenges involving entry, descent and landing (EDL). Heat shields brought from Earth incur a significant mass penalty in shield weight and propellant thus high cost. We propose a new massefficient and innovative way of protecting high-mass spacecraft during EDL. Heat shields fabricated in situ can provide a thermal-protection system for spacecraft that routinely enter a planetary atmosphere.

\section{State of the Art}

Selected past and current ablative heat shields
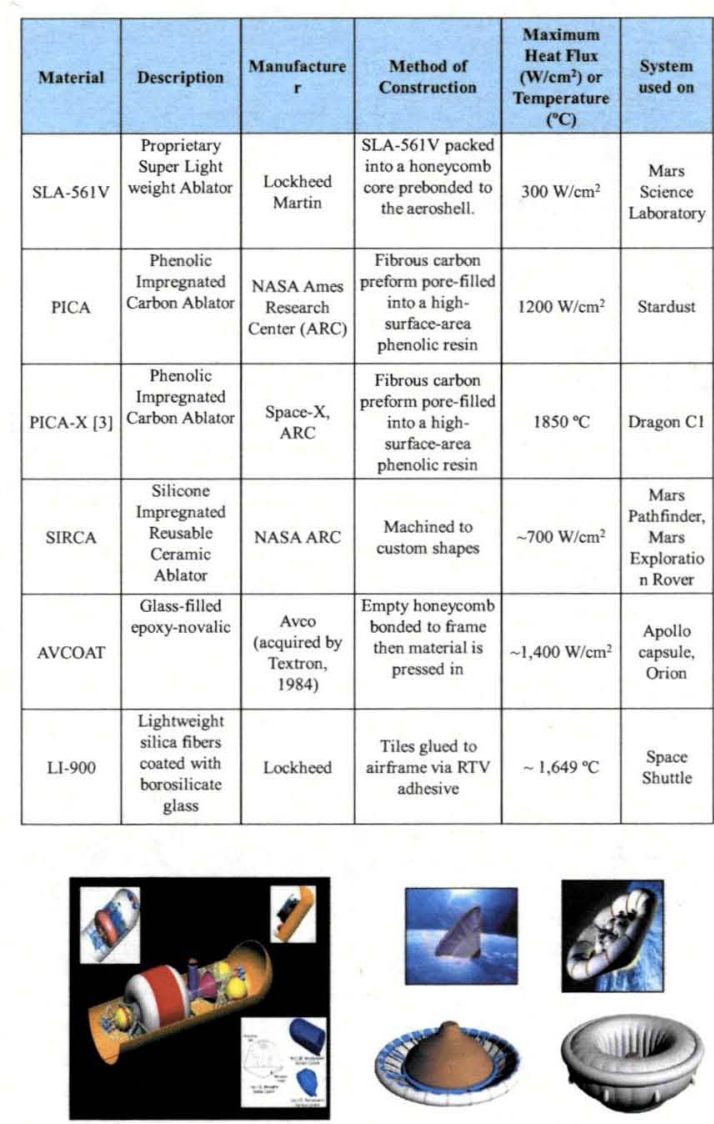

Currently proposed heat shield solutions that can be re-examined sintered tiles (Courtesy Dr. Phil Metzger/NASA KSC)

Sintered JSC-1A lunar regolith simulant

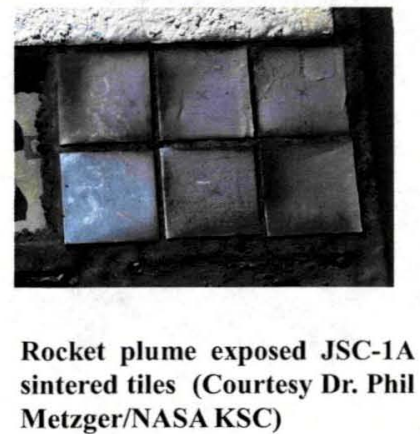

\section{Proposed Work}

Three regolith formation and manufacturing methods will be investigated.

1. Use the glass-melt left when oxygen is removed via ISRU (In Situ Resource Utilization) processes.

2. Compress then sinter the regolith.

3. Use an in-situ derived high-temperature polymer to bind regolith particles together. Also to look into methods to make the polymer binder in situ as well.

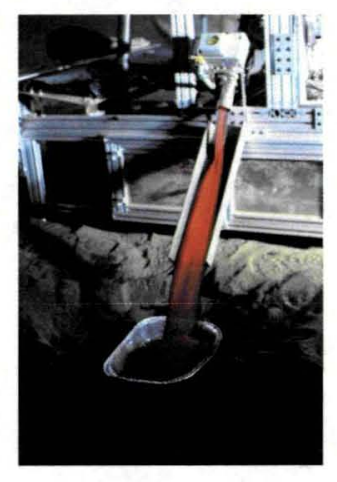

Hot Hawaiian tephra output from the roxygen generation I oxygen production reactor.

\section{Testing}

Testing will be performed at the Ames Research Center Arc Jet Facility. This facility can model the atmospheric entry environment.

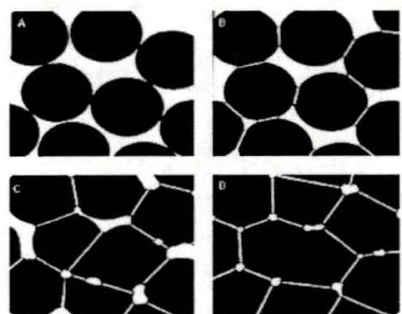

Schematic sequence $(A-D)$ of the sintering process.

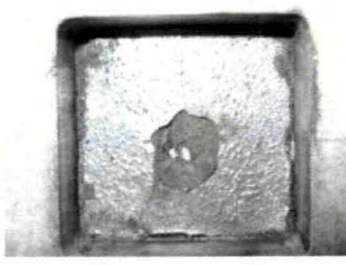

Regolith block made from polymer resin binding.
Acknowledgment

The authors wish to acknowledge the support of NASA, Kennedy Space Center, NASA Ames Research Center, and the National Institute for Advanced Concepts (NIAC) for support for this work.

\section{References}

M. Hogue, R. Mueller, P. Hintze, L. Sibille, D. Rasky, "Regolith-Derived Heat Shield for Planetary Body Entry and Descent System with In Situ Fabrication”, Submitted to Earth \& Space 2012 Conference, Pasadena, CA, April 15 - 18, 2012.

M. Hogue, R. Mueller, D. Rasky, "Regolith-Derived Heat Shield for Planetary Body Entry and Descent System with In Situ Fabrication”, NIAC proposal, 2011. 